\title{
Evaluation of the Impact of the PABBS Suicide Bereavement Training on Clinicians' Knowledge and Skills
}

\author{
A Pilot Study
}

\author{
Sharon McDonnell ${ }^{1,2}$, Pauline A. Nelson ${ }^{3} \odot$, Sarah Leonard¹, Barry McGale², \\ Carolyn A. Chew-Graham ${ }^{4,5}$, Nav Kapur ${ }^{1,6,9}$, Jenny Shaw ${ }^{1}$, Shirley Smith7, and Lis Cordingley ${ }^{8}$ \\ 'The Centre for Mental Health and Safety, The University of Manchester, UK \\ 2Suicide Bereavement UK, Manchester, UK \\ ${ }^{3}$ Alliance Manchester Business School, The University of Manchester, UK \\ 4Primary Care and Health Sciences, Keele University, UK \\ ${ }^{5}$ West Midlands CLAHRC, Coventry, UK \\ ${ }^{6}$ Greater Manchester Mental Health Trust, Manchester, UK \\ IIf U Care Share Foundation, Durham, UK \\ ${ }^{8}$ Division of Musculoskeletal and Dermatological Research and Manchester Biomedical Research Centre, University of Manchester, UK \\ ${ }^{9}$ NIHR Patient Safety Translational Research Centre, The University of Manchester, UK
}

\begin{abstract}
Background: Health-care professionals do not routinely receive training on how best to support parents bereaved by suicide. Evidence-based training - Postvention Assisting Those Bereaved by Suicide (PABBS) - was designed to address this gap. Aims: The study aimed (a) to pilot PABBS training and evaluate its perceived effectiveness (impact on self-reported knowledge, skills and confidence) in managing suicide bereavement; and (b) to explore training acceptability. Method: A pre- and postevaluation design was used. Professionals attended intensive, structured 1-day PABBS training comprising: didactic/interactive teaching; practice-orientated activities supported with real-life materials and a manual/workbook. Evaluation forms completed immediately before and after training analyzed: (a) self-reported changes in knowledge, skills, and confidence (perceived effectiveness of training); and (b) the acceptability of training. Results: In total, 62 professionals completed training. Perceived knowledge, skills, and confidence improved after training as did self-reported understanding, motivation to learn more, and intention to change practice. Training was highly rated, particularly the evidence-based, real-life materials, with some suggestions for improvement. Limitations: Self-selected sample and reliance on self-report measures are the study's limitations. Conclusion: PABBS training may help address gaps in professionals' capacity to support parents bereaved by suicide. The evidence-based content was highly acceptable and appeared to be a key ingredient in effecting self-reported changes in attitudes/intentions.
\end{abstract}

Keywords: suicide bereavement, postvention training, evidence-based training, evaluation, health professionals

Over 800,000 people worldwide die by suicide annually (World Health Organization, 2014). Each suicide may affect 135 people (Cerel et al., 2018), who may be at higher risk of dying by suicide themselves (Pitman, Osborn, Rantell, \& King, 2016).

Suicide bereavement is a complex global health issue (World Health Organization 2014). It may involve complicated mourning (Kolves \& De Leo, 2014), isolation, stigmatization, and lack of support (Department of Health, 2012; Pitman, Osborn, King, \& Erlangsen, 2014). Family members may be at elevated risk of self-harm or suicide, with mothers of the deceased at potentially highest risk (de Groot \& Kollen, 2013; McDonnell, 2006; Pitman et al., 2014;
Pitman et al., 2016). Parental bereavement has frequently been described as the most difficult type of bereavement an individual can experience (Mitchell, Kim, Prigerson, \& Mortimer-Stephens, 2004). Little is known about the effectiveness of postvention strategies (Andriessen et al., 2019). Those affected see general practitioners (GPs) as an important source of support but often rely on the voluntary sector alone and need help to navigate services (Ross, Kolves, \& De Leo, 2019; Wainwright et al., in press).

While UK guidelines for developing/evaluating suicide bereavement services stress the importance of primary care physicians/GPs being vigilant to the potential vulnerability of these families (Department of Health, 2012), 
many GPs are anxious and/or uncertain how to respond (Foggin et al., 2016; Halligan \& Corcoran 2001). It is known that some professionals are vulnerable to intense distress when a suicide occurs (Seguin et al., 2014) and do not receive training in suicide bereavement (Gibbons et al., 2019; Sanford, Cerel, McGann, \& Maple, 2016). Gaps in professionals' knowledge and training can be a barrier to providing better care; however, there are other, more complex challenges for professionals including feelings of powerlessness to help, especially if the deceased was also their patient (Foggin et al., 2016). Furthermore, the importance of developing theory-informed postvention training has been recognized (Andriessen, Castelli Dransart, Cerel, \& Maple, 2017).

To address these gaps, the Postvention Assisting Those Bereaved by Suicide (PABBS) training program was developed/piloted, aiming primarily to provide GPs and mental health professionals with the knowledge, skills, and confidence to respond to parents bereaved by suicide (a specific subgroup whose needs may be different from those of other family members). This paper reports the evaluation of the pilot to obtain preliminary indications of (a) perceived effectiveness of training and (b) training acceptability.

\section{Method}

\section{Development/Piloting}

Training was delivered in four 1-day workshops between August 2015 and February 2016 in the North of England. Content was largely based on findings from the PABBS study that ran from 2011 to 2015 (McDonnell et al., 2015) including: (a) exploration of parents' and health professionals' perceived needs (Foggin et al., 2016; Wainwright et al., in press); (b) best evidence about suicide bereavement support; and (c) a detailed content analysis of existing policy/training materials, for example, Grad (2012); NHS Scotland and Cruse Bereavement Care Scotland (2013); SAMH and NHS Scotland (2012); and SANE Australia (2012). Members of a local self-help suicide bereavement group formed part of the training development advisory group.

Delivery methods were designed in accordance with the perceived effectiveness of training framework (Perryman, 2014), acknowledging the importance of theory-informed approaches (Andriessen et al., 2017). Training focused on: suicide prevention; attitudes and stigma; suicide and its impact on health professionals; bereavement; suicide bereavement; parents bereaved by suicide; building resilience and instilling hope, with associated key learning objectives (Table 1). Training materials included lecture slides and high-quality short films made specifically for PABBS, highlighting key issues in the context of real practice. Issues included the experiences of parents bereaved

Table 1. Key learning objectives

\begin{tabular}{|c|c|c|}
\hline Training topics & Learning objectives & $\begin{array}{l}\text { Change targets } \\
\text { Knowledge }-\mathrm{K} \\
\text { Skills - S } \\
\text { Confidence-C }\end{array}$ \\
\hline 1. Suicide prevention & - Suicide statistics/extent & $\mathrm{K}, \mathrm{C}$ \\
\hline 2. Attitudes and stigma & - Attitudes to and language about suicide & $K, S, C$ \\
\hline 3. Suicide and its impact on health professionals & $\begin{array}{l}\text { - Impact on clinicians/importance of self-care (including support } \\
\text { systems for professionals) }\end{array}$ & $\mathrm{K}, \mathrm{C}$ \\
\hline 4. Bereavement & - Impact of bereavement in general & K \\
\hline 5. Suicide bereavement & $\begin{array}{l}\text { - GPs' and Suicide Liaison Officers' perspectives on caring for bereaved } \\
\text { parents }\end{array}$ & $K, S, C$ \\
\hline 6. Parents bereaved by suicide & $\begin{array}{l}\text { - Experiences of bereaved parents } \\
\text { - Parents' needs } \\
\text { - GPs'vulnerabilities/holistic view of parent/GP perspectives }\end{array}$ & $K, S, C$ \\
\hline 7. Building resilience and instilling hope & $\begin{array}{l}\text { - Guidance for clinicians on how to respond to/care for parents } \\
\text { bereaved by suicide } \\
\text { - Guidance on language use } \\
\text { - What individuals bereaved by suicide find helpful } \\
\text { - Where to signpost parents } \\
\text { - Good consultation practice } \\
\text { - Reflections on how training will change practice including action } \\
\text { plans on managing bereaved parents }\end{array}$ & $K, S, C$ \\
\hline
\end{tabular}


by suicide and those of clinicians responsible for their care; parents' needs; examples of good consultation practice. A manual/workbook supported learning. The mixed format included didactic sessions interspersed with presentations of the films, group discussion, as well as individual and group exercises. All activities aimed to advance and enhance trainees' understanding, motivation, and stimulate discussion.

\section{Evaluation Design: Quantitative/ Qualitative Questionnaire}

\section{Sampling and Recruitment}

Ethical approval was obtained from the National Research Ethics Service Committee North West (Reference: 11/ NW/21047). A convenience sample of participants was recruited between July 2015 and February 2016 by advertising via: (a) the staff intranet of an NHS Trust in the North of England; (b) Twitter; and (c) personal invitation of the research team. Participants were invited to attend one of four workshops as follows: staff of the NHS Trust who might come into contact with those bereaved by suicide (Workshop 1); individuals with specialist experience (i.e., up to 15 years of either working in suicide prevention/bereavement and/or delivering suicide prevention training), and individuals who had participated in the PABBS study or were known to the research team to be personally or professionally affected by suicide (Workshop 2); any professional in the UK who was interested in attending (Workshops 3 and 4).

\section{Data Collection}

During attendance at a workshop (free of charge) delegates completed a questionnaire to evaluate:

1) The perceived effectiveness of training. Immediately before/after training, participants scored (a) perceptions of their own knowledge, skills, and confidence in dealing with those bereaved by suicide and (b) perceived posttraining changes - positive, negative, or none - to understanding, confidence, motivations for/intentions to change practice.

2) Training acceptability. After training, participants scored the perceived usefulness of training tasks and gave written impressions of the training.

The questionnaire (Electronic Supplementary Material 1) comprised 38 items on a 5-point Likert scale, six items on a visual analogue scale, five yes/no items, and five freetext open questions. Perceived posttraining changes were measured with six simple numerical rating scales (NRSs) where scales ranged from +3 indicating positive change to -3 indicating negative change and 0 no change.
Following the unanticipated disclosure by several participants during Workshop 1 of having been personally/ professionally bereaved by suicide, subsequent workshop attendees were given the opportunity of recording their bereavement status, to capture the number of trainees directly affected.

\section{Data Analysis}

Data were analyzed with SPSS Version 23.0 (IBM Corp., 2015). The McNemar test was used to compare differences in the proportions of participants reporting sufficient knowledge, motivation, and confidence to deal with those bereaved by suicide pre-/posttraining. Descriptive summary statistics indicated self-reported changes scored in the NRS and the proportions of delegates reporting that training had influenced their knowledge, motivation, or confidence.

Free-text items were exported to Microsoft ${ }^{\circledast}$ Excel, and a qualitative content analysis (Schreier, 2012) enabled coding/segmentation of data on perceptions of training.

\section{Results}

Of 72 individuals initially agreeing to attend, six withdrew before training and four did not complete an evaluation questionnaire. The results presented here reflect the responses of 62 participants ( 38 female, 24 male) who completed both the training and the evaluation questionnaires.

Although training was aimed primarily at GPs and mental health professionals, 11 different professions were represented (Electronic Supplementary Material 2). Just under one-third were nurses $(32.3 \%)$, followed by GPs (11.3\%), therapists/counsellors (11.3\%), and social workers (9.7\%). Non-health-care professionals also attended, including coroners officers, police officers, and suicide bereavement charity staff. The majority had been working in this field for over 10 years; several had considerable expertise in suicide prevention, bereavement, and prevention training.

Of the 46 delegates attending Workshops 2, 3, and 4, $32.6 \%(n=15)$ reported having been personally bereaved by suicide and $87 \%(n=40)$ reported having been affected in a professional capacity.

\section{Perceived Effectiveness of Training}

McNemar's tests on the three pairs of pre-/posttraining evaluation items (Table 2) indicated statistically signifi- 
Table 2. Knowledge, skills, and confidence pre-/posttraining $(n=62)$

\begin{tabular}{|c|c|c|c|c|c|c|}
\hline & & \multicolumn{2}{|c|}{ Increased knowledge after training? ${ }^{d}$} & \multirow[b]{2}{*}{ Totals $n$} & \multirow{2}{*}{$\begin{array}{l}\text { McNemar test chi } \\
\text { square statistic }^{\mathrm{g}}\end{array}$} & \multirow[b]{2}{*}{ Significance } \\
\hline & & No & Yes & & & \\
\hline \multirow{2}{*}{$\begin{array}{l}\text { Sufficient knowledge before } \\
\text { training? }\end{array}$} & No & 1 & 37 & 38 & & \\
\hline & Yes & 3 & 21 & 24 & 27.23 & $p \leq .001$ \\
\hline \multirow[t]{3}{*}{ Totals } & & 4 & 58 & 62 & & \\
\hline & & \multicolumn{2}{|c|}{ Increased skills after training? ${ }^{\mathrm{e}}$} & & & \\
\hline & & No & Yes & & & \\
\hline \multirow{2}{*}{$\begin{array}{l}\text { Sufficient skills before } \\
\text { training? }\end{array}$} & No & 3 & 40 & 43 & & \\
\hline & Yes & 0 & 19 & 19 & 38.03 & $p \leq .001$ \\
\hline \multirow[t]{3}{*}{ Totals } & & 3 & 59 & 62 & & \\
\hline & & More confide & ter training? & & & \\
\hline & & No & Yes & & & \\
\hline \multirow{2}{*}{$\begin{array}{l}\text { Confident to respond before } \\
\text { training? }\end{array}$} & No & 2 & 39 & 41 & & \\
\hline & Yes & 1 & 20 & 21 & 34.23 & $p \leq .001$ \\
\hline Totals & & 3 & 59 & 62 & & \\
\hline
\end{tabular}

cant differences in the proportions of the 62 participants reporting improvements in knowledge, skills, and confidence before and after training (McNemar with Yates' correction, exact $p \leq .001$ for all three paired comparisons).

On all six NRS indicators, all participants, including specialists in the field, stated that their understanding of suicide bereavement had increased. Moreover, 90\% reported they now had fewer concerns about meeting bereaved parents in their future work. Self-reported motivation to learn more about suicide bereavement increased in $97 \%$ of cases; $81 \%$ reported intentions to find out more about suicide bereavement in the 2-3 months following training and 99\% were more motivated to discuss this with colleagues. Furthermore, $97 \%$ reported intentions to make changes to practice. Electronic Supplementary Material 3 shows that median scores for each of the six NRS items were either 2 or 3 (where the maximum possible score for each was 3 ).

\section{Training Acceptability}

Questionnaire responses indicated that the vast majority of individual tasks were perceived as quite/very useful in relation to content, relevance, and potential to advance understanding (Electronic Supplementary Material 4). Approximately two-thirds $(67 \%)$ reported that the training day contained the right amount of material; all agreed/ strongly agreed that the materials were informative/of high quality and the facilitators were well prepared/successful in stimulating interest in suicide bereavement (Electronic Supplementary Material 5). All but one respondent
(98.3\%) reported that they would recommend the training to colleagues, while 57 of 61 (93.4\%) indicated that they would not want to receive an online-only version (although $86 \%$ would value supplementary online resources to consolidate learning following face-to-face training).

The free-text qualitative data offered a further level of insight into delegates' perspectives on training acceptability. Three key themes are presented with brief illustrative data extracts.

\section{Useful Aspects}

Increased awareness of the impact of suicide bereavement on both parents and professionals, the potentially longer duration of bereavement, and the importance of continuity of support for parents/self-care for professionals were noted:

Clear information regarding what families find helpful; effect on practitioners professionally and personally when a person ends their life by suicide. (P39)

The real-life experiences linked to practical exercises and skill-building helped increase confidence:

Real life examples helped to relate to the theory. (P56)

Sharing information and networking with other professionals from a range of backgrounds and services helped consolidate learning:

... having the opportunity to share experiences with other ... agencies i.e. police and coroners officers, was invaluable. (P30) 


\section{Intended Changes to Practice}

Delegates reported intentions to more proactively support individuals bereaved by suicide (i.e., less fear of making an approach/being direct/using techniques):

Gives me the confidence to open up discussions about people's experiences of being bereaved by suicide. (P19)

There were expressed intentions to share learning with colleagues to support them to manage suicide bereavement:

Up-skill team now on information learnt - difference between suicide bereavement and bereavement. (P5)

Delegates intended to use the knowledge and confidence gained to push for/develop/improve services:

... more of an "evidence-based" rationale to argue a point with management/service directors. (P8)

\section{Suggested Improvements}

Delegates suggested a longer duration of training as it was so packed with valuable information/exercises:

It's such an important issue that ... it needs adequate training time - felt a bit rushed ... and ... more discussion would have been really helpful. (P10)

Many suggested a re-balancing of content to focus more on activities/skill-building with some of the knowledge elements put online or sent to participants in advance:

I think some of the videos could be viewed online. (P3)

Other suggestions were that the experiences/perspectives of other professionals could be included:

...could be broadened to cover a wide variety of health specialties, if not "professionals" in general. (P12)

It was also suggested that case studies of particularly challenging suicide bereavement scenarios could be included to deepen learning:

Coping with situations when things go wrong. (P37)

\section{Discussion}

To our knowledge, PABBS is the first international, evidence-based, theory-informed suicide bereavement training. It improved the perceived self-reported knowledge, skills, and confidence of a wide range of professionals in supporting parents bereaved by suicide. Further, self-reported understanding of suicide bereavement and moti- vation/intention to learn more and change practice also increased after training. The acceptability of training was rated highly with some suggestions for improvement.

GPs have an important role in the care of bereaved families after suicide (Clark \& Ebert, 2017). Despite training being specifically designed for GPs and mental health professionals, we received a high volume of interest from diverse professionals and chose not to restrict the training to certain groups during the pilot/evaluation phase to respond to this clear unmet need. Despite the variation in professions, a high proportion of delegates reported positive changes in knowledge, skills, and confidence after training while almost all reported fewer concerns about meeting bereaved families. This suggests that PABBS training may help to address previously identified gaps in professionals' expertise (Foggin et al., 2016; Pitman, Osborn, King, \& Erlangsen, 2014), for specialists and nonspecialists alike, and go some way to addressing the needs of bereaved families (Ross et al., 2019). Although PABBS was piloted in the UK, it has international relevance since suicide bereavement is a globally recognized phenomenon. Postvention support is considered to be a key aspect of suicide prevention internationally (Andriessen et al., 2019; World Health Organization, 2018) since support/ training are protective factors (Castelli Dransart, Treven, Grad, \& Andriessen, 2017).

\section{Feedback and Suggestions for Improvement}

The evidence-based content was highly acceptable and appeared to be a key ingredient in effecting self-reported changes in attitudes/intentions. This is encouraging, considering the diversity of the professions attending.

Several suggested that the training be delivered over 2 days, or slides be reduced/content made available online so that time could be dedicated to skills-building activities and that training could be widened to a greater range of professionals and include studies of particularly challenging cases.

\section{Ethical Issues}

An unexpected characteristic of the sample was the relatively high proportion of delegates who disclosed personal/professional experience of suicide bereavement, highlighting the potential vulnerability of professionals attending training (Marzano, Smith, Long, Kisby, \& Hawton, 2016). PABBS training is particularly informed by the work of Grad (2012) such that self-care is a key tenet. Eth- 
ically, it is essential that: (a) trainers are adequately skilled/ qualified to appropriately support attendees; and (b) more than one trainer delivers these programs to ensure that attendees receive one-to-one support should they need it. (National Action Alliance for Suicide Prevention, 2014, 2015).

\section{Limitations and Strengths}

The generalizability of findings is limited owing to the self-selected sample of relatively small size and reliance on nonstandard, study-specific, self-report measures alone. There was no control group to act as a comparator or to help identify potential confounders of the results. An important caveat is that the experience of being participants could have led to these findings alone, rather than changes being attributable to the specific content of this training (Brown, 1992).

It could also be argued that professionals bereaved/affected by suicide might be attracted to such training. The pre-/post-self-reported knowledge, skills, and confidence items were not identical and thus interpretation of these results should be undertaken with some caution. We do not have evidence that immediate changes identified would be maintained over time, nor is it known if newly acquired knowledge or skills would translate into changes in practice. However, participants expressed clear intentions to use the skills/knowledge learned and PABBS stands as a useful guide for developing future suicide bereavement training.

Despite these limitations, the study is the first known evaluation of a suicide bereavement training program that (1) is informed both by academic research and a theory of training delivery, (b) is delivered by recognized experts in the field of suicide prevention, and (c) formally evaluates both the perceived effectiveness and acceptability of training in frontline professionals with a high likelihood of interacting with those bereaved by suicide. A particular strength is in highlighting the importance of trainers with skills in dealing with unexpected/unresolved issues that might be evoked for trainees.

\section{Training Implications}

This study supports the view that specialist training is required for professionals who come into contact with those bereaved by suicide (Hawton \& Simkin, 2003). The development of evidence-based suicide bereavement training is in its infancy but is a key aspect of suicide pre- vention, requiring postvention policies worldwide to support it.

Arguably, international suicide prevention strategies need to pay more attention to the needs of frontline staff, who are exposed to suicide or suicide bereavement. Additionally, although online training may be perceived as "cheaper," if delivered in isolation without appropriate face-to-face support, it could be potentially unethical. Indeed, over $90 \%$ of participants in this study were opposed to online training alone.

GPs were only the second largest group of professional participants in this study, suggesting that it may be difficult to engage GPs in postvention training. Postvention strategies may need to be mindful of this issue and adopt measures to address it. Campaigns to raise awareness of the importance of such training and/or making postvention training mandatory may be of benefit.

Ideally, training evaluations should address both real-time (immediate) and long-term effectiveness. We were only able to capture immediate changes; however, longerterm changes to practice as well as maintenance of attitude shifts and knowledge gains should all be assessed qualitatively/quantitatively to inform appropriate modifications to training, as well as inform decisions about frequency of updates or refresher sessions.

\section{Future Research}

PABBS training responds to the call to increase theory-informed research in the postvention field (Andriessen et al., 2017; Neimeyer, Cerel, \& Maple, 2017); however, there is also a need to increase intercultural collaboration and build bonds between research and practice.

Specifically in relation to postvention training, it is understandable in the current economic climate that organizations are developing online methods of delivery as a potentially cheaper solution. Future research should explore the benefits and drawbacks associated with delivering postvention training online, including whether it adequately supports trainees who are themselves bereaved/ impacted by suicide. Additionally, if PABBS training is effective in improving knowledge skills and confidence among professionals, it will be important to assess its impact on people bereaved by suicide themselves.

\section{Conclusion}

There is evidence that PABBS training helped improve the self-reported knowledge, skills, and confidence of a wide 
range of professionals in supporting parents bereaved by suicide. In addition, reported understanding of suicide bereavement, motivation to learn more, and intentions to change practice all increased.

The provision of PABBS training is a step in the right direction in acknowledging and addressing the emotional, practical, and training needs of professionals since it responds to a previously unmet need and fills a training gap both in the United Kingdom and beyond. This type of training should be included as a key objective in future suicide prevention strategies and form a key part of future postvention research.

\section{Electronic Supplementary Material}

The electronic supplementary material is available with the online version of the article at https://doi. org/10.1027/0227-5910/a000646

ESM 1. Evaluation questionnaire items

ESM 2. Delegates by professional group

ESM 3. Understanding, concerns, motivations, and intentions post-training

ESM 4. Perceived usefulness of training tasks

ESM 5. Perceptions of materials, training day, and facilitators

\section{References}

Andriessen, K., Castelli Dransart, D. A., Cerel, J., \& Maple, M. (2017). Current postvention research and priorities for the future: Results of a survey. Crisis, 38(3), 202-206. https://doi. org/10.1027/0227-5910/a000459

Andriessen, K., Krysinska, K., Hill, N. T. M., Reifels, L., Robinson, J., Reavley, N., \& Pirkis, J. (2019). Effectiveness of interventions for people bereaved through suicide: A systematic review of controlled studies of grief, psychosocial and suicide-related outcomes. BMC Psychiatry, 19, 49. https://doi.org/10.1186/ s12888-019-2020-z

Brown, A. L. (1992). Design experiments: Theoretical and methodological challenges in creating complex interventions in classroom settings. Journal of the Learning Sciences, 2(2), 141-178. https://doi.org/10.1207/s15327809jls0202_2

Castelli Dransart, D. A., Treven, M., Grad, O. T., \& Andriessen, K. (2017). Impact of client suicide on health and mental health professionals. In K. Andriessen, K. Krysinska \& O. T. Grad (Eds.), Postvention in action: The international handbook of suicide bereavement support (pp. 245-254). Boston, MA: Hogrefe Publishing.

Cerel, J., Brown, M., Maple, M., Singleton, M., Van De Venne, J., Moore, M., \& Flahert, C. (2018). How many people are exposed to suicide? Not six. Suicide and Life-Threatening Behaviour, 49(2), 529-534. https://doi.org/10.1111/sltb.12450

Clark, S., \& Ebert, L. (2017). After suicide: Roles of the general practitioner. In K. Andriessen, K. Krysinska, \& O.T. Grad (Eds.), Postvention in action: The international handbook of suicide bereavement support (pp. 150-161). Boston, MA: Hogrefe Publishing. de Groot, M., \& Kollen, B. J. (2013). Course of bereavement over 8-10 years in first degree relatives and spouses of people who committed suicide: Longitudinal community based cohort study. BMJ, 347, f5519. https://doi.org/10.1136/bmj.f5519

Department of Health. (2012). Preventing suicide in England - a cross-government outcomes strategy to save lives. London, UK: HM Government.

Foggin, E., McDonnell, S., Cordingley, L., Kapur, N., Shaw, J., \& Chew-Graham, C. (2016). GPs' experiences of dealing with parents bereaved by suicide: A qualitative study. British Journal of General Practice, 66(651), 737-746. https://doi.org/10.3399/ bjgp16X686605

Gibbons, R., Brand, F., Carbonnier, A., Croft, A., Lascelles, K., Wolfart, G., \& Hawton, K. (2019). Effects of patient suicide on psychiatrists: survey of experiences and support required. BJPsych Bulletin, 43(5), 236-241. https://doi.org/10.1192/bjb.2019.26

Grad, O. T. (2012). Guidelines to assist clinical staff after the suicide of a patient. Retrieved from https://www.iasp.info/resources/ detail/guidelines-to-assist-clinical-staff-after-the-suicide-ofa-patient-1426.htm

Halligan, P., \& Corcoran, P. (2001). The impact of patient suicide on rural general practitioners. British Journal of General Practice, 51(465), 295-296.

Hawton, K., \& Simkin, S. (2003). Helping people bereaved by suicide. British Medical Journal, 327(7408), 177-178. https://doi. org/10.1136/bmj.327.7408.177

Kolves, K., \& De Leo, D. (2014). Is suicide grief different? Data from empirical studies. In D. De Leo, A. Cimitan, K. Dyregrov, O. Grad, \& K. Andriessen (Eds.), Bereavement after traumatic death: Helping the survivors (pp. 159-171). Boston, MA: Hogrefe Publishing.

Marzano, L., Smith, M., Long, M., Kisby, C., \& Hawton, K. (2016). Police and suicide prevention: Evaluation of a training program. Crisis, 37(3), 194-204. https://doi.org/10.1027/0227-5910/a000 381

McDonnell, S. (2006). A study to identify the experiences of parents bereaved by suicide of undetermined death (Unpublished doctoral dissertation). University of Manchester, UK.

McDonnell, S., Cordingley, L., Chew-Graham, C., Kapur, N., Shaw, J., McGale, B., \& Smith, S. (2015). The development of a parental suicide bereavement training pack for health professionals. Retrieved from https://suicidebereavementuk.com/ development-parental-suicide-bereavement-training-packhealth-professionals

Mitchell, A., Kim, Y., Prigerson, H., \& Mortimer-Stephens, M. (2004). Complicated grief in survivors of suicide. Crisis, 25(1), 12-18. https://doi.org/10.1027/0227-5910.25.1.12

National Action Alliance for Suicide Prevention: Clinical Workforce Preparedness Task Force. (2014). Suicide prevention and the clinical workforce: Guidelines for training. Retrieved from https://theactionalliance.org/sites/default/files/guidelines.pdf

National Action Alliance for Suicide Prevention: Survivors of Suicide Loss Task Force. (2015). Responding to grief, trauma, and distress after a suicide: U.S. national guidelines. Washington, DC. Retrieved from https://www.sprc.org/sites/default/files/migrate/ library/RespondingAfterSuicideNationalGuidelines.pdf

Neimeyer, R. A., Cerel, J., \& Maple, M. (2017). Recommendations for research on suicide loss: A commentary. Death Studies, 41(10), 673-679. https://doi.org/10.1080/07481187.2017.1335555

NHS Scotland and Cruse Bereavement Care Scotland. (2013). More questions than answers: Supporting people bereaved by suicide. Retrieved from http://www.chooselife.net/Training/mqta.aspx

Perryman, K. (2014). Synthesising existing and developing new evidence on effective healthcare professional training that aims to improve the management of psychological distress in primary care (Unpublished doctoral dissertation). University of Manchester, UK.

Pitman, A., Osborn, D., King, M., \& Erlangsen, A. (2014). Effects of suicide bereavement on mental health and suicide risk. The 
Lancet Psychiatry, 1(1), 86-94. https://doi.org/10.1016/S22150366(14)70224-X

Pitman, A. L., Osborn, D. P. J., Rantell, K., \& King, M. B. (2016). Bereavement by suicide as a risk factor for suicide attempt: $A$ cross-sectional national UK-wide study of 3432 young bereaved adults. BMJ Open, 6, e009948. https://doi.org/10.1136/ bmjopen-2015-009948

Ross, V., Kolves, K., \& De Leo, D. (2019). Exploring the support needs of people bereaved by suicide: A qualitative study. OMEGA Journal of Death and Dying. Advance online publication. https:// doi.org/10.1177/0030222819825775

SAMH and NHS Scotland. (2012). After a suicide. Retrieved from https://www.samh.org.uk/documents/After_a_suicide.pdf

SANE Australia. (2012). SANE bereavement guidelines. Retrieved from https://www.sane.org/images/PDFs/1408_proj_glbereave ment.pdf

Sanford, R., Cerel, J., McGann, V., \& Maple, M. (2016). Suicide loss survivors' experiences with therapy: Implications for clinical practice. Community Mental Health Journal, 52(5), 551-558. https://doi.org/10.1007/s10597-016-0006-6

Schreier, M. (2012). Qualitative content analysis in practice. Thousand Oaks, CA: Sage.

Seguin, M., Bordeleau, V., Drouin, M.-S., Castelli-Dransart, D. A., \& Giasson, F. (2014). Professionals' reactions following a patient's suicide: Review and future investigation. Archive of Suicide Research, 18(4), 340-362. https://doi.org/10.1080/13811118. 2013.833151

Wainwright, V., Cordingley, L., Chew-Graham, C., Kapur, N., Shaw, J., Smith, S., ... McDonnell, S. (in press). Experiences of support and perceived needs of parents bereaved by suicide: A qualitative study. British Journal of General Practice.

World Health Organization. (2014). Preventing suicide: A global imperative. Geneva, Switzerland: Author.

World Health Organization. (2018). National suicide prevention strategies: Progress, examples and indicators. Retrieved from https://apps.who.int/iris/bitstream/handle/10665/279765/ 9789241515016-eng.pdf?sequence=1\&isAllowed =y

\section{History}

Received January 11, 2019

Revision received August 12, 2019

Accepted August 28, 2019

Published online January 10, 2020

\section{Acknowledgments}

The authors would like to thank the parents and clinicians who participated in the research; those who attended the pilot workshops and provided comprehensive feedback; Pennine Care NHS Foundation Trust, who collaborated with the University of Manchester to develop the training.

\section{Conflict of Interest}

Sharon McDonnell is Managing Director of Suicide Bereavement UK, a company specializing in suicide bereavement research, consultancy, and training. She delivers PABBS training on an ongoing basis.

Barry McGale delivers PABBS training on an ongoing basis. Carolyn A Chew-Graham is a practicing GP.

Nav Kapur is the topic expert for the NICE suicide prevention guidelines in the community and custodial settings and sits on the Suicide Prevention Advisory Group at the Department of Health (England).

Shirley Smith is the Founder of IF U Care Share Foundation, a charity that supports people bereaved by suicide and she sits on the Suicide Prevention Advisory Group at the Department of Health (England).

All authors (except Pauline Nelson and Sarah Leonard who analyzed the data) are authors of the PABBS evidence-based suicide bereavement training program.

\section{Funding}

The National Institute for Health Research (NIHR) Research for Patient Benefit Programme funded the development of the training (Grant Reference PB-PG-0110-21047); West Midlands Academic Health Science Network funded a pilot workshop.

This article presents independent research funded by the $\mathrm{Na}$ tional Institute for Health Research (NIHR) under its Research for Patient Benefit Programme (Grant Reference PB-PG-0110-21047). The views expressed are those of the author(s) and not necessarily those of the NHS, the NIHR or the Department of Health and Social Care.

\section{ORCID}

Pauline A. Nelson

(D) https://orcid.org/0000-0003-4162-4736

\section{Pauline A. Nelson}

Alliance Manchester Business School

The University of Manchester

Booth Street East

Manchester M13 9SS

UK

pauline.nelson@manchester.ac.uk

Sharon McDonnell is Managing Director of Suicide Bereavement UK, a company specializing in suicide bereavement research, consultancy, and training and Honorary Research Fellow, University of Manchester, UK

Pauline A. Nelson is Research Fellow in Health Services Research at the Alliance Manchester Business School, University of Manchester, UK.

Sarah Leonard is Research Associate in the Centre for Mental Health and Safety, University of Manchester, UK.

Barry McGale is Director of the National Suicide Research Foundation, Ireland, and Patron for the Support After Suicide Partnership, England, UK.

Carolyn A. Chew-Graham is GP Principal and Professor of General Practice Research, Keele University (with a focus on mental health research) and Chair of the Society of Academic Primary Care (SAPC), UK.

Nav Kapur is Professor of Psychiatry and Population Health at the University of Manchester and an Honorary Consultant Psychiatrist at Greater Manchester Mental Health NHS Foundation Trust, UK.

Jenny Shaw is Professor of Forensic Psychiatry, University of Manchester, and Honorary Consultant Psychiatrist, Greater Manchester Mental Health, Manchester, UK.

Shirley Smith is the Founder of IF U Care Share Foundation, UK, a charity that supports people bereaved by suicide.

Lis Cordingley is Senior Lecturer in Health Psychology at the University of Manchester, UK. 